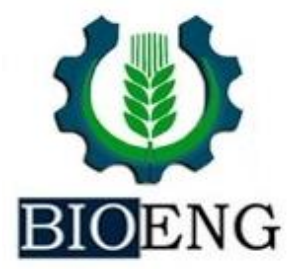

\title{
MORFOLOGIA DE FRUTOS E QUALIDADE FÍSICA E FISIOLÓGICA DE SEMENTES DE CULTIVARES DE JILOEIRO
}

\author{
A. R. Martins' ${ }^{1}$ H. A. Paraíso ${ }^{1}$, L. S. P. Gomes ${ }^{2 *}$, C. A. Costa ${ }^{1}$, D. S. \\ Brandão Júnior ${ }^{1}$, J. C. dos Santos ${ }^{2}$ \\ ${ }^{1}$ UNIMONTES - Universidade Estadual de Montes Claros, Montes Claros, MG, Brasil. \\ ${ }^{2}$ UFMG - Universidade Federal de Minas Gerais, Montes Claros, MG, Brasil
}

Article history: Received 31 October 2018; Received in revised form 01 December 2018; Accepted 07 December 2018; Available online 19 December 2018.

\begin{abstract}
RESUMO
Objetivou-se com este trabalho determinar aspectos morfológicos de frutos e da qualidade física e fisiológica de semente de cultivares de jiloeiro (SolanumgiloRaddi). O experimento foi realizado no Laboratório de Análises de Sementes do Instituto de Ciências Agrárias da Universidade Federal de Minas Gerais (LAS- ICA/UFMG). As cultivares foram Gigante Jaíba, Compridogrande rio, Morro redondo e Comprido verde-claro. Determinou-se o teor de umidade, massa de mil sementes, massa fresca e massa seca dos frutos e sementes, germinação, emergência, contagem de plântulas normais, além do índice de velocidade de germinação e emergência. O delineamento experimental foi inteiramente casualizado com quatro repetições. Os resultados foram submetidos à análise de variância, adotando-seo teste de Tukey a 5\% de probabilidade. A cultivar Gigante Jaíba destacou-se por apresentar os maiores resultados para massa frescae seca e massa de mil sementes. Os testes de germinação e vigor foi possível separar as sementes das cultivares em diferentes níveis de qualidade fisiológica, destacando-se as cultivares Gigante Jaíba e Comprido grande rio.
\end{abstract}

Palavras-chave: Solanum gilo Raddi; biometria; germinação.

\section{FRUIT MORPHOLOGY AND PHYSICAL AND PHYSIOLOGICAL QUALITY OF SEEDS OF JILOEIRO CULTIVARS}

\begin{abstract}
The objective of the work was to determine the morphological aspects of fruits and the physical and physiological quality of the seed of cultivars of jiloeiro (Solanum gilo Raddi). The experiment was carried out at the Laboratory of Production Analysis of the Institute of Agricultural Sciences of the Federal University of Minas Gerais (LAS - ICA / UFMG). As cultivars were the Gigante Jaíba, the Compridogrande river, the Round Morro and the Long Green. Determination of moisture content, fresh and dry mass of fruits and seeds, germination, emergence, normal seedling counting, germination and emergence rate index. The experimental design was completely randomized with four replicates. The results were submitted to analysis of variance, thus adopting the $5 \%$ probability test. A cultivar Gigante Jaíba stood out for presenting the results of fresh dry mass and mass of one thousand seeds. The testes of germination and vigor were possible as cultivars of cultivars at different levels of physiological quality, standing out as cultivars Gigante Jaíba and Comprido Grande Rio.
\end{abstract}

Keywords: Solanum gilo Raddi; biometrics; germination.

\footnotetext{
"luanspg@hotmail.com
} 


\section{INTRODUÇÃO}

O jiloeiro (Solanum gilo Raddi) é uma hortaliça de clima tropical, cuja área de plantio vem aumentando progressivamente nos últimos anos, principalmente na região sudeste do Brasil (Alves, et al., 2017). Apresenta propriedades nutracêuticas e seu comércio tem contribuído com a renda de diversas famílias. Só em Minas Gerias, foram comercializados de 2010 a 2015, mais de 13 mil toneladas anuais de jiló, valor esse que representa mais do que o dobro da quantidade total comercializada de berinjela, espécie da mesma família, mais difundida e consumida no mundo (Pinheiro et al., 2015).

A cultura do jiló é caracterizada por apresentar uma grande variabilidade em relação ao formato e coloração de seus frutos. Na caracterização de 43 genótipos de jiloeiro, Morgado e Dias (1992), constataram frutos de formatos alongados, ovais, achatados e redondos. Além disso, observaram variações nas colorações dos mesmos em brancos, mesclados, verdeclaros e verde-escuros. As características morfológicas dos frutos são de grande importância no processo de comercialização, pois estes devem estar dentro dos padrões exigidos pelo mercado consumidor (Souza et al., 2017).

As sementes também podem fornecer informações relevantes, principalmente, quando associadas a qualidade morfológica dos frutos.As características presentes nos frutos e sementes podem auxiliar na formação de lotes de sementes mais uniformes, distinção de espécies e cultivares, estudos de dispersão, estabelecimento de plântulas e no processo de colheita. Na literatura, existem poucos

\section{MATERIAL E MÉTODOS}

O experimento foi conduzido no Laboratório de Análise de Sementes do Instituto de Ciências Agrárias da Universidade Federal de Minas Gerais, Campus Regional de Montes Claros. Para as análises foram utilizados frutos das trabalhos que relacionam as características morfofisiológicas dos frutos e sementes de jiloeiro com a qualidade fisiológica das sementes.

A qualidade de sementes é um aspecto imprescindível na indústria sementeira, existem vários tipos de testes passíveis de serem empregados, e as características avaliadas podem ser de natureza morfológica, fisiológica, citológica e bioquímica (Brasil, 2009). A viabilidade de sementes,por exemplo, para fins de comércio é determinada pelo teste padrão de germinação podendo ser facilmente reproduzido (Panoff, 2013; Resende et al., 2015).

Além da análise de viabilidade de sementes, pode-se empregar testes que determinam o vigor das sementes. Estes têm sido auxiliares ao teste de germinação, uma vez que este apresenta limitações por ser realizado sob condições controladas, dessa forma, pode não representar as condições reais de campo. Assim, os testes de vigor revelam diferenças de desempenho entre lotes de sementes durante o armazenamento ou em campo (Carvalho; Nakagawa, 2000).

A alta qualidade de sementes é fundamental para se alcançar estande ideal de plantas (Resende et al., 2015). Desta forma, o sucesso da produção, depende, dentre outros aspectos, do estabelecimento de plântulas no campo, fator este, diretamente relacionado com a germinação e vigor das sementes (Pereira et al., 2007).

Diante destas considerações, este trabalho teve como objetivo determinar os aspectos morfológicos de frutos e avaliação da qualidade física e fisiológica de sementes de cultivares de jiloeiro.

cultivares de jiló (Solanum gilo Raddi.): Gigante Jaíba, Compridogrande rio, Comprido verde-claro e Morro redondo. Os frutos foram coletados 65 dias após antese, com maturação evidenciada pela coloração . Foram determinados a massa 
fresca e seca $(\mathrm{g})$ e mensurados $o$ comprimento, largura e a espessura em centímetros de três frutos por repetição, sendo utilizadas quatro repetições por parcela.

Posteriormente, os frutos foram deixados em repouso por 48 horas para extração manual das sementes em água. As sementes obtidas foram deixadas sobre papel toalha em temperatura ambiente por três dias para pré - secagem, sendo armazenadas para as análises subsequentes em frascos de vidro com tampa.

A caracterização morfológica das sementes foi determinada medindo-se o comprimento, largura e espessura, em milímetros, com auxílio de paquímetro digital (precisão de $0,01 \mathrm{~mm}$ ), utilizando quatro repetições de 25 sementes por parcela. $\mathrm{O}$ formato da semente foi estimado em função do coeficiente $\mathrm{J}$, obtido pela relação entre comprimento e largura $(\mathrm{C} / \mathrm{L})$ e do coeficiente $\mathrm{H}$, com base na relação espessura/largura (E/L), conforme classificação proposta por Puerta-Romero (1961). Já a classificação das sementes quanto a cor do tegumento foi realizada de acordo com a metodologia proposta por Munsell (1975).

Para a caracterização física das sementes de jiló foram avaliadas as características: grau de umidade, matéria fresca e seca e massa de 1000 sementes, utilizando-se quatro repetições de 50 sementes por cultivar. $\mathrm{O}$ teste de determinação do grau de umidade foi realizado empregando-se o método padrão de estufa a $105 \pm 3{ }^{\circ} \mathrm{C}$ por 24 horas, conforme preconizado nas Regras de Análise de Sementes (Brasil, 2009). Os valores de matéria fresca e seca foram obtidos por pesagem das sementes em balança analítica (precisão 0,0001g), sendo a matéria seca determinada, após secagem das sementes em estufa de circulação forçada de ar a $65{ }^{\circ} \mathrm{C}$ por 72 horas. A massa de 1000 sementes foi estimada por pesagem de quatro subamostras de 50 sementes provenientes da porção "semente pura" de cada cultivar.

A avaliação da qualidade fisiológica foi realizada os testes de germinação e emergência de plântulas. No teste de germinação adotou-se o delineamento inteiramente casualizado (DIC), com quatro repetições de 50 sementes puras por tratamento. As sementes foram distribuídas em substrato papel mata-borrão, umedecido com água destilada 2,5 vezes o seu peso seco e colocadas em caixa plástica tipo gerbox. As caixas permaneceram em um germinador do tipo incubador refrigerado à temperatura variável de $20^{\circ} \mathrm{C}$ (16 horas) e $30{ }^{\circ} \mathrm{C}(8$ horas). A contagem de plântulas normais, caracterizadas pela presença de estruturas essenciais intactas foi realizada no $6^{\circ}$ e $14^{\circ}$ dia após a instalação do teste, conforme (Brasil, 2009).O vigor das sementes foi estimado por avaliação dos dados de primeira contagem de germinação, índices de velocidade de germinação e emergência, biometria e matéria seca das plântulas normais. $\mathrm{O}$ índice de velocidade de germinação (IVG), foi calculado empregando-se a fórmula proposta por Maguire (1962), pelas contagens diárias, no mesmo horário, do número de sementes que tiveram protrusão de raiz primária durante os 14 dias de avaliação. Após esse período, as plântulas normais, foram medidas quanto ao comprimento com auxílio de paquímetro digital e suas estruturas colocadas em cadinhos de alumínio, acondicionadas em estufa com circulação forçada de ar à temperatura de $65{ }^{\circ} \mathrm{C}$, durante 72 horas. Ao final desta etapa as plântulas foram pesadas em balança de precisão de $0,001 \mathrm{~g}$ para obtenção da massa seca (Cavalcante et al., 2012). Para determinação do percentual de emergência e do índice de velocidade de emergência (IVE), as sementes foram semeadas a profundidade de $2 \mathrm{~cm} \mathrm{em}$ bandejas brancas de polietileno, com 20x27x6 centímetros de dimensão, contendo areia umedecida com água a $60 \%$ da capacidade de retenção, conforme preconizado pelas Regras de Análise de Sementes (Brasil, 2009).

Após o plantio, as bandejas foram acondicionadas em germinador à temperatura de $20^{\circ} \mathrm{C}$ (16 horas) e $30^{\circ} \mathrm{C}$ ( 8 horas). As contagens foram realizadas 
diariamente por 14 dias, sendo consideradas emergidas, plântulas que apresentavam cotilédones acima da superfície da areia. O IVE foi calculado segundo a fórmula proposta por Maguire (1962), em que: IVE = E1/N1 + E2/N2,onde: IVE = índice de velocidade de emergência, E1, E2 = número de

\section{RESULTADOS E DISCUSSÃO}

Os frutos da cultivar Gigante Jaíba exibiram médias de 860,55 gramas de massa fresca e 85,13 gramas de massa seca, diferindo estatisticamente dos demais cultivares. Da mesma forma, os valores médios para comprimento $(12,81 \mathrm{~cm})$, largura $(8,82 \mathrm{~cm})$ e espessura $(1,43 \mathrm{~cm})$, foram superiores. Já para 'Comprido plântulas normais computadas na primeira contagem e na segunda contagem e N1, N2 = número de dias da semeadura à primeira e segunda contagem

Os dados obtidos foram submetidos à análise de variância, adotando-se o teste de Tukey ao nível de 5\% de probabilidade.

Tabela 1. Tamanho, massa fresca e massa seca de frutos de jiló

\begin{tabular}{cccccc}
\hline \multirow{2}{*}{ Cultivares } & \multicolumn{2}{c}{ Tamanho do fruto $(\mathrm{cm})$} & \multicolumn{2}{c}{ Média $(\mathrm{g})$} \\
\cline { 2 - 6 } & Comprimento & Largura & Espessura & Massa fresca & Massa seca \\
\hline Morro redondo & $4,46 \mathrm{c}^{*}$ & $4,70 \mathrm{~b}$ & $0,30 \mathrm{~b}$ & $104,0 \mathrm{~b}$ & $10,32 \mathrm{~b}$ \\
Gigante Jaíba & $12,81 \mathrm{a}$ & $8,82 \mathrm{a}$ & $1,43 \mathrm{a}$ & $860,55 \mathrm{a}$ & $85,13 \mathrm{a}$ \\
Comprido grande rio & $5,74 \mathrm{~b}$ & $4,22 \mathrm{~b}$ & $0,36 \mathrm{~b}$ & $131,50 \mathrm{~b}$ & $12,18 \mathrm{~b}$ \\
Comprido verde-claro & $6,50 \mathrm{~b}$ & $4,20 \mathrm{~b}$ & $0,29 \mathrm{~b}$ & $153,50 \mathrm{~b}$ & $14,67 \mathrm{~b}$ \\
\hline $\mathrm{CV}(\%)$ & 7,78 & 8,47 & 22,23 & 35,78 & 22,32 \\
\hline
\end{tabular}

*Médias seguidas de mesma letra na coluna não diferem entre si em nível de $5 \%$ de probabilidade, pelo teste de Tukey.

A translocação de fotoassimilados para o fruto e a absorção de água são parâmetros para o aumento da massa de matéria fresca e seca, contribuindo no crescimento do fruto (Neto; Reinhardt, 2003).O tamanho e a forma são características de cada cultivar, podendo ser diferentes. O conhecimento da variação biométrica de caracteres dos frutos é importante para o melhoramento dos atributos de importância econômica (Lasmar, 2010).

As características morfológicas e coloração de tegumento das sementes apresentaram variações entre os quatro acessos. Porém, de acordo com o modelo proposto por Puerta-Romero (1961), em relação à forma, todas os cultivares tiveram as sementes classificadas como esféricas e achatadas. O cultivar Gigante Jaíba grande rio', 'Comprido verde-claro' e 'Morro redondo' não diferiram entre si em relação a largura, espessura e as massas de matéria fresca e secados frutos. Houve maior variabilidade dos frutos principalmente em relação ao comprimento (Tabela 1). 
Tabela 2. Características da forma e tamanho de sementes

\begin{tabular}{|c|c|c|c|c|c|c|}
\hline \multirow{2}{*}{ Cultivares } & \multicolumn{2}{|c|}{ Coeficientes } & \multirow{2}{*}{ Forma } & \multicolumn{3}{|c|}{ Tamanho (mm) } \\
\hline & $\mathrm{J}$ & $\mathrm{H}$ & & Comprimento & Largura & Espessura \\
\hline Morro redondo & 1,3 & 0,2 & $\begin{array}{l}\text { Esférica e } \\
\text { achatada }\end{array}$ & $2,8 \mathrm{c}$ & $2,1 \mathrm{c}$ & $0,5 \mathrm{~d}$ \\
\hline Gigante Jaíba & 1,3 & 0,3 & $\begin{array}{c}\text { Esférica e } \\
\text { achatada }\end{array}$ & $3,6 \mathrm{a}$ & $2,8 \mathrm{a}$ & $0,7 \mathrm{a}$ \\
\hline Comprido grande rio & 1,4 & 0,3 & $\begin{array}{l}\text { Esférica e } \\
\text { achatada }\end{array}$ & $3,4 \mathrm{~b}$ & $2,5 \mathrm{~b}$ & $0,7 \mathrm{~b}$ \\
\hline $\begin{array}{l}\text { Comprido verde- } \\
\text { claro }\end{array}$ & 1,3 & 0,2 & $\begin{array}{l}\text { Esférica e } \\
\text { achatada }\end{array}$ & $3,4 \mathrm{~b}$ & $2,5 \mathrm{~b}$ & $0,6 \mathrm{c}$ \\
\hline $\mathrm{CV}(\%)$ & & & & 1,88 & 2,16 & 3,37 \\
\hline
\end{tabular}

*Médias seguidas de mesma letra na coluna não diferem entre si em nível de $5 \%$ de probabilidade, pelo teste de Tukey.

Quanto à coloração do tegumento das sementes, foi possível aferir que a cor amarela é característica das cultivares Comprido grande rio, Comprido verdeclaro e Morro redondo, com pouca variação na intensidade. Já na'Gigante Jaíba', a classificação da cor segundo a metodologia descrita por Munsell (1975) é vermelho-amarelado (Tabela 3). Alguns trabalhos vêm tentando associar a coloração do tegumento de sementes com o potencial fisiológico em diferentes espécies. Segundo Krzyzanowski e França Neto (2001) a alteração de coloração do tegumento de sementes é considerada um dos fatores associados a deterioração e consequentemente a perda do potencial fisiológico.Sementes mais coloridas e brilhantes possuem na composição química do tegumento maiores teores de lignina, suberina e cutina, ocasionando maior proteção quando comparado a sensibilidade das sementes mais claras (Marcos Filho, 2005). Desta forma, a cor do tegumento nas sementes da cultivar Gigante Jaíba pode apresentar vantagem em relação as outras, principalmente se tratando do tempo e das condições de armazenamento.

Entre as avaliações da qualidade física foi possível perceber que em relação ao teor de umidade das sementes não houve diferença ao nível de $5 \%$ de probabilidade. Essa uniformidade é adequada para a padronização das avaliações dos testes de qualidade fisiológica (Loeffler et al., 1988). A relação obtida entre a massa de matéria fresca e seca variou de acordo com o teor de água das mesmas.

Tabela 3. Caracterização da cor do tegumento da semente usando metodologia de Munsell (1975)

\begin{tabular}{lcc}
\hline \multirow{2}{*}{ Cultivares } & \multicolumn{2}{c}{ Cor do tegumento } \\
\cline { 2 - 3 } & Munsell (1975) & Tradução \\
\hline Morro redondo & $2,5 \mathrm{Y}-8 / 4$ & Amarelo \\
Gigante Jaíba & $7,5 \mathrm{YR}-6 / 8$ & Vermelho amarelado \\
Comprido grande rio & $2,5 \mathrm{Y}-8 / 6$ & Amarelo \\
Comprido verde-claro & $2,5 \mathrm{Y}-8 / 6$ & Amarelo \\
\hline
\end{tabular}

Comparando-se os resultados para massa de 1000 sementes (Tabela 4) é possível observar que variaram de 2,14 a 5 gramas, com destaque para a cultivar 
Gigante Jaíba que apresentou maior média. Em estudos realizados por Pereira et al. (1980), em sementes de jiló cultivar Tinguá, foram encontradas diferentes médias para massa de 1000 sementes, sendo que, sementes com maiores médias apresentaram também maior porcentagem e velocidade de germinação. A massa de 1000 sementes é importante para o cálculo da densidade de semeadura, além da extração de informações a respeito do tamanho (Brasil, 2009).

Tabela 4. Médias do teor de umidade, massa de mil sementes e massa fresca e seca de sementes

\begin{tabular}{lcccc}
\hline Cultivares & $\begin{array}{c}\text { Umidade } \\
(\%)\end{array}$ & $\begin{array}{c}\text { Massa de } 1000 \text { sementes } \\
(\mathrm{g})\end{array}$ & $\begin{array}{c}\text { Massa fresca } \\
(\mathrm{g})\end{array}$ & $\begin{array}{c}\text { Massa seca } \\
(\mathrm{g})\end{array}$ \\
\hline Morro redondo & 7,98 & $2,14 \mathrm{c}$ & $0,106 \mathrm{~b}$ & $0,097 \mathrm{~b}$ \\
Gigante Jaíba & 9,88 & $5,0 \mathrm{a}$ & $0,254 \mathrm{a}$ & $0,222 \mathrm{a}$ \\
Comprido grande rio & 9,78 & $2,39 \mathrm{~b}$ & $0,115 \mathrm{~b}$ & $0,107 \mathrm{~b}$ \\
Comprido verde-claro & 8,86 & $2,37 \mathrm{~b}$ & $0,113 \mathrm{~b}$ & $0,102 \mathrm{~b}$ \\
\hline \multicolumn{1}{c}{$\mathrm{CV}(\%)$} & 13,06 & 3,57 & 6,27 & 3,75 \\
\hline
\end{tabular}

Médias seguidas de mesma letra na coluna não diferem entre si em nível de $5 \%$ de probabilidade, pelo teste de Tukey.

Os melhores resultados quanto a massa fresca e seca das sementes também foi apresentada pelo a cultivar Gigante Jaíba. As cultivares Morro redondo, Comprido verde-claro e Comprido grande rio não se diferenciaram e apresentaram menores médias para ambos os parâmetros. O máximo acúmulo de massa seca está diretamente associado ao grau de maturidade fisiológica das sementes, que pode ser prejudicado quando os frutos são coletados imaturos, ou ainda, após o ponto ideal de maturação pelo efeito de deterioração. Uma semente após atingir a máximamassa seca passa a sofrer decréscimo devido as perdas no processo de respiração (Carvalho; Nakagawa, 2000).Os valores de massa fresca e seca, assim como os outros testes físicos e morfológicos efetuados, pressupõe que a cultivar Gigante Jaíba apresentará potencial fisiológico superior aos demais cultivares.Entretanto, essa diferença encontrada pode ser atribuída ao potencial genético de cada cultivar.

Segundo Popinigis (1985), a constituição genética dentro de uma mesma espécie também pode influenciar a qualidade fisiológica da semente. Em trabalho realizado com sementes de pimenta (Capsicum frutescens), aquelas que apresentaram maior massa seca e tamanho, proporcionaram também melhores percentuais de germinação, índice de velocidade de germinação e desenvolvimento inicial de plântulas (Mengarda; Lopes, 2012).

Os resultados relativos ao teste de qualidade fisiológica apresentados na (Tabela 5), indicaram que a cultivar Gigante Jaíba obteve maior porcentagem de germinação $(90,5 \%)$. As cultivares Morro redondo e Comprido verde-claro apresentaram desempenho inferior (78\%).Vale ressaltar que todas as cultivares apresentaram médias superiores ao padrão mínimo para comercialização, que é de $75 \%$ de germinação (Brasil, 2009). Foram observadas variações significativas nos testes de primeira contagem de germinação e índice de velocidade de germinação. $O$ teste de primeira contagem de germinação conseguiu expressar bem a diferença na velocidade de germinação, classificando as cultivares Gigante Jaíba e Comprido grande rio como as de maior vigor. As cultivares Morro redondo e Comprido verde-claro demonstraram desempenhos parecidos, porém inferiores aos demais.

Quanto ao comprimento e massa seca das plântulas normais, observou-se que a cultivar Gigante Jaíba apresentou-se superior. Pode-se sugerir que a causa tenha sido a relação entre a massa e tamanho das sementes, com maior transferência de 
reservas para o embrião, de forma mais eficiente.

Tabela 5. Germinação (G), primeira contagem de plântulas normais (PC), índice de velocidade de germinação (IVG), comprimento (CP) e massa seca (MS) de plântulas normais, emergência (E) e índice de velocidade de emergência (IVE).

\begin{tabular}{lccccccc}
\hline Cultivares & $\mathrm{G}(\%)$ & $\mathrm{PC}(\%)$ & $\mathrm{IVG}$ & $\mathrm{CP}(\mathrm{mm})$ & $\mathrm{MS}(\mathrm{g})$ & $\mathrm{E}(\%)$ & $\mathrm{IVE}$ \\
\hline Morro redondo & $78,0 \mathrm{~b}$ & $66 \mathrm{~b}$ & $55,39 \mathrm{~b}$ & $48,15 \mathrm{~b}$ & $0,042 \mathrm{c}$ & 76,5 & $33,49 \mathrm{~b}$ \\
Gigante Jaíba & $90,5 \mathrm{a}$ & $86 \mathrm{a}$ & $76,06 \mathrm{a}$ & $68,77 \mathrm{a}$ & $0,077 \mathrm{a}$ & 86,5 & $46,58 \mathrm{a}$ \\
Comprido grande rio & $84,5 \mathrm{ab}$ & $80 \mathrm{a}$ & $70,90 \mathrm{a}$ & $48,99 \mathrm{~b}$ & $0,055 \mathrm{~b}$ & 78 & $36,66 \mathrm{~b}$ \\
Comprido verde-claro & $78,0 \mathrm{~b}$ & $67 \mathrm{~b}$ & $57,57 \mathrm{~b}$ & $48,82 \mathrm{~b}$ & $0,052 \mathrm{c}$ & 72,5 & $36,49 \mathrm{~b}$ \\
\hline CV $(\%)$ & 6,96 & 7,74 & 7,93 & 5,51 & 7,36 & 7,51 & 7,47 \\
\hline *Médias seguidas de mesma letra na & coluna não diferem entre & si em nível de & $5 \%$ & de \\
probabilidade, pelo teste de Tukey.
\end{tabular}

Para a cultura do tomate (Solanum lycopersicum), foi demonstrado que o tamanho inicial de plântulas está relacionado positivamente ao uso de sementes maiores, com a obtenção de melhor taxa de sobrevivência de plântulas, bem como maior competitividade dentro e entre espécies (Khan et al., 2012).

Os testes de emergência e índice de velocidade de emergência são importantes para presumir o desempenho das sementes no estabelecimento de plântulas (Pereira, 2012). O resultado expresso pela emergência de plântulas deve revelar pequenas diferenças de vigor em lotes de sementes com germinação semelhante (Torres, 2002). Embora o índice de velocidade de emergência tenha

\section{CONCLUSÃO}

A cultivar Gigante Jaíba destacou-se por apresentar os maiores resultados para massa fresca, seca e massa de 1000 sementes.

Os testes de germinação e vigor permitiram separar as sementes das

\section{REFERÊNCIAS}

Alves, M. V. P. Von Pinho, E. V. R.; Santos, H. O.; Alves, C. P. G, Pereira, R. W. Physiological and Biochemical Characterization of Jiló Seeds (Solanum gilo) in Different Harvest Times. distinguido a cultivar Gigante Jaíba das demais, a emergência final, analisada no $14^{\circ}$ dia após a instalação do experimento, não detectou interação entre as cultivares (Tabela 5). A identificação do potencial fisiológico dos lotes de médio vigor muitas vezes é difícil, pois pode ocorrer variações no seu comportamento, ora se igualando aos lotes de maior ora aos de menor vigor, dependendo do teste empregado (Marcos filho, 1999).

Vale ressaltar que é importante a avaliação do vigor com base em mais de um teste, principalmente em sementes de hortaliças, que são sensíveis às alterações provocadas pela deterioração após a maturidade fisiológica (Marcos filho, 2005).

cultivares em diferentes níveis de qualidade fisiológica, destacando-se as cultivares Gigante Jaíba e Comprido Grande rio.
American Journal of Plant Sciences. 2017. v.8, p.2569-2595.

Alves, C. Z.; Godoi, A. R.; Candido, A.C. S.; Oliveira, N.C. Qualidade fisiológica de 
sementes de jiló pelo teste de envelhecimento acelerado. Ciência Rural v. 42, n. 1, p.58-63, 2012.

Brasil. Ministério da Agricultura, Pecuária e Abastecimento. Regras para análise de sementes / Ministério da Agricultura, Pecuária e Abastecimento. Secretaria de Defesa Agropecuária. - Brasília: Mapa/ACS, 2009. 399 p.

Carvalho, N. M.; Nakagawa, J. Sementes: ciência, tecnologia e produção. 4 ed. Jaboticabal: Funep, 2000. 588p.

Cavalcante, V. S.; Santos, V. R.; Santos Neto, A. L.; Santos, M. A. L.; Santos, C. G.; Costa, L. C. Biomassa e extração de nutrientes por planta de cobertura. Revista Brasileira de Engenharia agrícola e Ambiental, v.16, n.5, p. 521-528, 2012.

Gaspar, C. M.; Nakagawa, J. Influência do tamanho na germinação e no vigor de sementes de milheto (influência do tamanho na germinação e no vigor de sementes de milheto (Pennisetum americanum (L.) Leeke). Revista Brasileira de Sementes, v. 24, n. 1, p.339344, 2002.

Khan, N.; Kazmi, R.H.; Willems, L. A. J; Van Heusden, A. W.; Ligterink, W.; Hilhorst, H.W.M. Exploring the Natural Variation for Seedling Traits and Their Link with Seed Dimensions in Tomato. 2012.

Krzyzanowski, F. C.; França Neto, J. B. Trabalho técnico: Vigor de sementes. v.11, n.3, p. 81-84, 2001.

Lasmar, A. Herança de caracteres relacionados ao formato e cor de frutos em jiló. Lavras: UFLA, 40 p, 2010.

Loeffler, T. M.; Tekrony, D. M.; Egli, D. B. The bulk conductivity test as an indicator of soybean seed quality. Journal of Seed Technology, Lansing, v.12, n.1, p.37-53, 1988.
Maguire, J. D. Speed of germination aid in selection and evaluation for seedling emergence and vigor. Crop Science, v.2, n.2, p. 176-177, 1962.

Marcos Filho, J. Fisiologia de sementes de plantas cultivadas. Piracicaba: FEALQ. 495 p, 2005.

Marcos Filho J. 1999. Testes de vigor: importância e utilização. In: Krzyzanowsk I, F. C; Vieira, R.D; FrançaNeto, J. B (ed). Vigor de sementes: conceitos e testes. Londrina: ABRATES. cap.1. p. 1-21.

Mengarda, L. H. G; Lopes, J. C. Qualidade de sementes e desenvolvimento inicial de plântulas de pimenta malagueta e sua relação com a posição de coleta de frutos. Revista Brasileira de Sementes, v. 34, n. 4, p. 644 - 650, 2012.

MUNSELL SOIL COLOR COMPANY. Munsell soil color charts, Baltimore, 1975. V.1 117p.

Morgado, H. S.; Dias, M. J. V. Caracterização da coleção de germoplasma de jiló no CNPH/Embrapa. Horticultura Brasileira, Brasília, v.10, n.2, p.8688,1992.

Neto, M. T. C.; Reinhardt, D. H. Relação entre os parâmetros de crescimento do fruto de manga cv. Haden.Revista Brasileira de Fruticultura, Jaboticabal, v. 25, n. 1, 2003.

Panoff, B. Detecção do gene de peroxidase em sementes de soja pela reação da polimerase em cadeia (PCR). 2013.

Pereira, R. S; Nascimento, W. M; Vieira, J. V. Germinação e vigor de sementes de cenoura sob condições de altas temperaturas. Horticultura Brasileira, v.25, p. 215-219, 2007.

Pereira, A. L.; Silva, E. M.; Costa, F. A.; Mendes, F. Influência da idade do fruto 
sobre a qualidade da semente do jiló. Revista brasileira de sementes - Ano 2nº 1. Brasília DF, 1980.

Pereira, E. M. Avaliação da qualidade fisiológica de sementes de pimenta e pimentão por meio da atividade respiratória. Lavras: UFLA. 69 p, 2012.

Pereira, R. B. Doenças e pragas do jiloeiro. Concórdia: Embrapa hortaliças, 2012. 13 p. (Embrapa hortaliças. Circular técnica 106).

Pinheiro, J. B.; Pereira, R. B.; Freitas, R. A.; Melo, R. A. C. Coleção plantar:A cultura do jiló. Brasília, DF: Embrapa, 70 p, 2015.

Popiniguis, F. Fisiologia de sementes. Agiplan. 1985, Brasília. 289 p.
Puerta-Romero, J. Variedades de judias cultivadas em España. Madrid: Ministério de agricultura /INIA, 789p., 1961.

Rezende, R. G.;Jesus, L. L.; Nery, M. C.; Rocha, A. S.; Cruz, S. M.; Andrade, P. C. R. Teste de tetrazólio em sementes de crambe. Semina: Ciências Agrárias, v. 36, n. 4, 2015.

Souza, C. L. M. et al. Características biométricas de frutos e caracterização fisiológica de sementes de espécies de Physalis (Solanaceas. Revista Brasileira de Ciências Agrárias (Agrária), v. 12, n. 3, p. 277-282, 2017.

Torres, S. B. Métodos para avaliação do potencial fisiológico de sementes de melão. Piracicaba - SP. 103 p, 2002. 